\title{
The Interaction between Fluid Wall Shear Stress and Solid Circumferential Strain Affects Endothelial Gene Expression
}

\author{
Ronny Amaya, Alexis Pierides, John M. Tarbell* \\ Department of Biomedical Engineering, City College of New York, City University of New York, New York, \\ New York, 10031, United States of America \\ * tarbell@ccny.cuny.edu
}

\section{Abstract}

Endothelial cells lining the walls of blood vessels are exposed simultaneously to wall shear stress (WSS) and circumferential stress (CS) that can be characterized by the temporal phase angle between WSS and CS (stress phase angle - SPA). Regions of the circulation with highly asynchronous hemodynamics (SPA close to $-180^{\circ}$ ) such as coronary arteries are associated with the development of pathological conditions such as atherosclerosis and intimal hyperplasia whereas more synchronous regions (SPA closer to $0^{\circ}$ ) are spared of disease. The present study evaluates endothelial cell gene expression of 42 atherosclerosisrelated genes under asynchronous hemodynamics $\left(\mathrm{SPA}=-180^{\circ}\right)$ and synchronous hemodynamics $\left(\mathrm{SPA}=0^{\circ}\right)$. This study used a novel bioreactor to investigate the cellular response of bovine aortic endothelial cells (BAECS) exposed to a combination of pulsatile WSS and $C S$ at $S P A=0$ or $S P A=-180$. Using a PCR array of 42 genes, we determined that BAECS exposed to non-reversing sinusoidal WSS $\left(10 \pm 10 \mathrm{dyne} / \mathrm{cm}^{2}\right)$ and CS $(4 \pm 4 \%)$ over a 7 hour testing period displayed 17 genes that were up regulated by SPA $=-180^{\circ}$, most of them pro-atherogenic, including NFKB and other NFKB target genes. The up regulation of $\mathrm{NFKB}$ p50/p105 and p65 by SPA $=-180^{\circ}$ was confirmed by Western blots and immunofluorescence staining demonstrating the nuclear translocation of NFKB p50/p105 and p65. These data suggest that asynchronous hemodynamics $\left(\mathrm{SPA}=-180^{\circ}\right)$ can elicit proatherogenic responses in endothelial cells compared to synchronous hemodynamics without shear stress reversal, indicating that SPA may be an important parameter characterizing arterial susceptibility to disease.

Copyright: @ 2015 Amaya et al. This is an open access article distributed under the terms of the Creative Commons Attribution License, which permits unrestricted use, distribution, and reproduction in any medium, provided the original author and source are credited.

Funding: This work was supported by National Institutes of Health Grant HL 086543. The funders had no role in study design, data collection and analysis, decision to publish, or preparation of the manuscript.

Competing Interests: The authors have declared that no competing interests exist.

\section{Introduction}

The fluid wall shear stress (WSS) driven by pulsatile blood flow and the solid circumferential stress (CS) driven by pulsatile blood pressure and associated strain, act simultaneously on endothelial cells (EC) lining blood vessels modulating their biological activity. Due to distal impedance at a vascular site of interest (global effect) and the inertial effects of blood flow at 


\section{Hemodynamic Forces relationship and SPA}

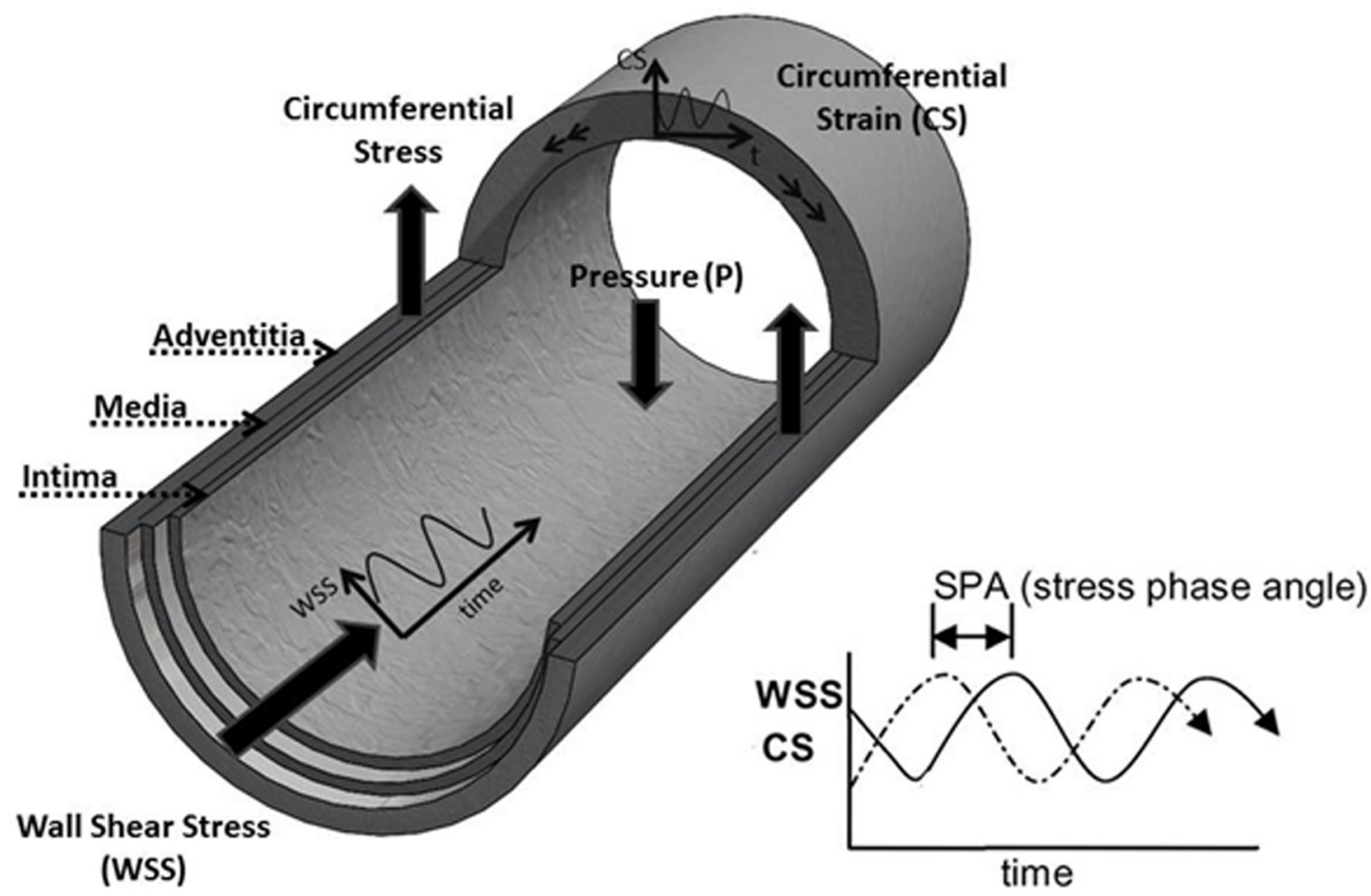

Fig 1. Simultaneous WSS and CS on EC are characterized by the SPA. Blood flow in the axial direction induces wall shear stress (WSS) and the changes in pressure during the cardiac cycle induce circumferential strain and circumferential stress (CS) on the EC lining the wall of the blood vessel. Due to impedance of the distal circulation, local inertial effects associated with flow in larger vessels and arterial geometry, there is a time lag between WSS and CS characterized by the stress phase angle-SPA $=\varphi($ CS-WSS)

doi:10.1371/journal.pone.0129952.g001 
the relationship between hemodynamics and atherosclerosis since the work of $\mathrm{Ku}$ et al. [10]. We believe the SPA should be included as an important hemodynamic parameter as well because it measures the degree of asynchrony between the main biomechanical forces acting on the EC (CS and WSS), combining solid mechanics and fluid mechanics.

To further support the hypothesis that SPA is an important parameter, we have used a novel hemodynamic simulator to compare gene expression profiles (39 target genes and 3 housekeeping genes) of BAECs under highly asynchronous, atheroprone hemodynamics (SPA $=-180^{\circ}$ ) with atheroprotective, synchronous hemodynamics $\left(\mathrm{SPA}=0^{\circ}\right)$. BAECs were chosen since they have been utilized extensively as a model system for the study of mechanical effects on EC. A limited set of genes was investigated rather than a large array because the SPA is still not widely accepted as an important mechanical factor in EC mechano-stimulation. We observed that the expression of 17 out of 39 genes differed significantly after exposure to identical WSS and CS waveforms that differed only by the SPA $\left(0^{\circ}\right.$ or $\left.-180^{\circ}\right)$.

\section{Materials and Methods}

Cell culture components obtained from Sigma (St. Louis, MO) include: bovine serum albumin (BSA, 30\% solution), trypsin, penicillin streptomycin, MEM (phenol red free), sodium bicarbonate, fibronectin, fetal bovine serum (FBS), L-Glutamine. Dulbecco's PBS (1x without Ca2 + and $\mathrm{Mg} 2+$ ) from Fisher Scientific (Houston, TX).

BAECs were purchased from VEC Technologies (Rensselaer, NY) and grown in T-75 flasks with 10\% FBS-MEM. Silicone sheets (Down Corning Corporation, MI) were used as the substrates for cell culture. BAECs were seeded onto the upper surface of silicone membranes of 0.020 " thickness. First the membranes were laser cut to the geometrical specifications of the bioreactor, and then silicone substrates were washed for $20 \mathrm{~min}$ with a gentle detergent and autoclaved for 30 minutes. A region delimited by an area of $1.5 \times 4.5 \mathrm{~cm}$ on each substrate was coated using bovine plasma fibronectin ( $30 \mu \mathrm{g} / \mathrm{ml}$ in MEM) for 1 hour at room temperature. The BAECs between passages 3 and 7 were plated at a density of $1.0 \times 10^{5} \mathrm{cells} / \mathrm{cm}^{2}$ onto the treated silicone substrates. ECs were grown using with $10 \%$ FBS until confluency in a controlled environment (37C and $5 \% \mathrm{CO}_{2}$ air). The EC monolayer reached confluence within four days.

\section{Gene expression}

At the end of the stretch and shear experiments, RNA was isolated using TRIzol reagent (Invitrogen) following the manufacture's protocol. RNA was purified using the RNeasy kit (Invitrogen), and then purified RNA was converted into cDNA by reverse transcription (RT). For analyzing gene expression, quantitative real-time PCR (RT-qPCR) was performed for 42 genes on the ABI PRISM 7000 sequence detection system (Applied Biosystems). Using the geNorm algorithm, ßactin, B2M, and HPRT were determined to be the best performing housekeeping genes (HKG) and the geometric mean quantities of the HKG were used as the normalization factor [11]. The PCR reactions were performed in $25-\mu l$ reaction mixture volumes containing SYBR Green PCR Master Mix (Applied Biosystems), primer pairs, and cDNA. The programs for RT-qPCR were set to $15 \mathrm{~min}$ at $95^{\circ} \mathrm{C}$, followed by 40 cycles of $17 \mathrm{~s}$ at $95^{\circ} \mathrm{C}, 30 \mathrm{~s}$ at $54^{\circ} \mathrm{C}$, and $30 \mathrm{~s}$ at $72^{\circ} \mathrm{C}$. Gene expression was calculated using the DDCt method. Following each PCR, dissociation curve analysis was used to evaluate the specificity of product amplification. Primer sequences are listed in (Table A in S1 File). The gene list is given below in Table 1.

\section{Fluorescence inmunostaining}

At the end of the experiments silicone membranes with confluent monolayers were stained with specific antibodies for NFKB p50/p105 (Santacruz, California), NFKB p65 (Cell Signaling, 
Table 1. Atherosclerosis Related Gene List (43 genes) for PCR Array.

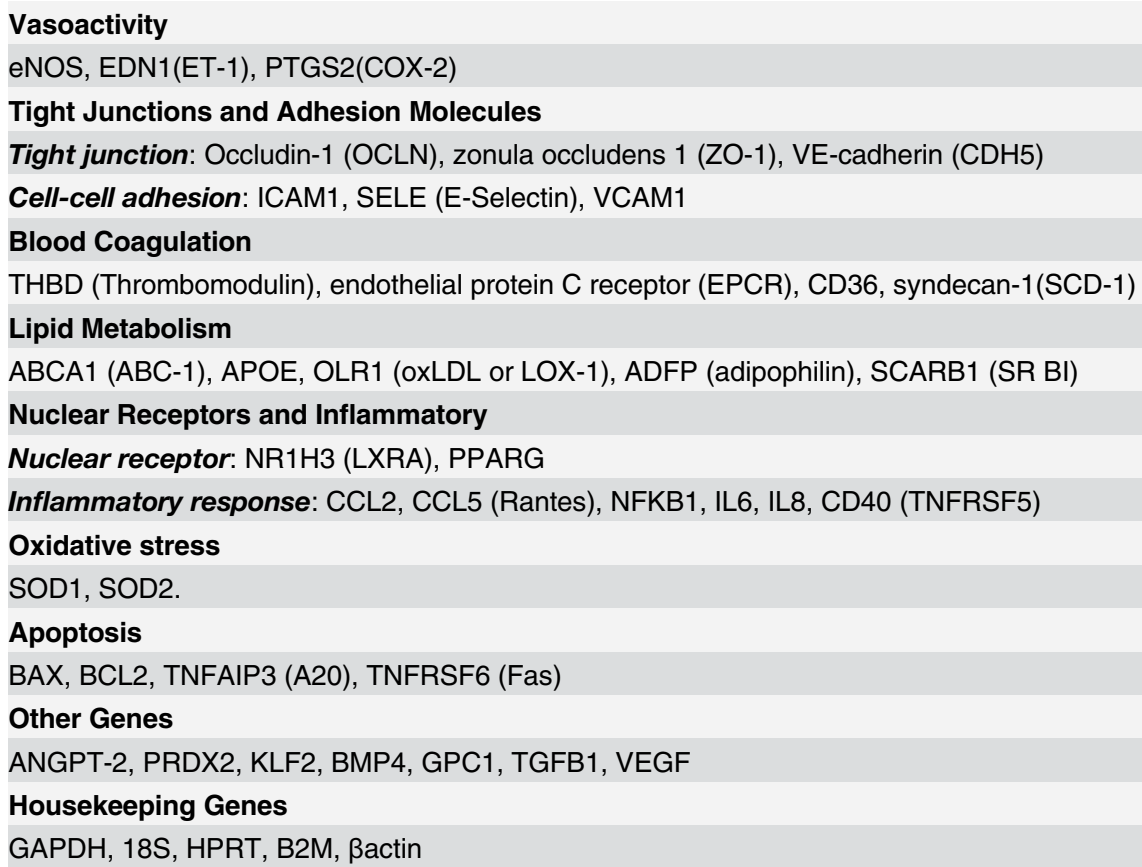

Massachusetts) and CDH5 and visualized using fluorescence microscopy. Silicone membranes were washed twice with PBS and fixed in 1\% PFA and 4\% PFA for NFKB p65 for 10 min, cut into sections, and permeabilized with Triton X-100 in PBS for $10 \mathrm{~min}$. After permeabilization samples were blocked in 10\% BSA and $0.1 \%$ Triton X-100 in PBS (NFKB and CDH5) for $1 \mathrm{~h}$. After washing with $0.1 \%$ Triton X-100 in PBS, the silicone sheets were incubated with polyclonal rabbit anti- NFKB, and CDH5 primary antibodies overnight at $4^{\circ} \mathrm{C}$ followed by washing with $0.1 \%$ Triton X-100 in PBS. Samples were subjected to secondary antibody Alexa Fluor 488 donkey anti-rabbit (1:500 to 1:200; Invitrogen) secondary antibody for $1.5 \mathrm{~h}$ for CDH5 and with secondary antibody Alexa Fluor 488 donkey anti-goat (1:100 to 400; Santa Cruz) for 1.5h for NFKB. Samples were washed again with $0.1 \%$ Triton X-100 in PBS and mounted with vectashield mounting media with DAPI on glass slides with cover slips in contact with cells. These slides were imaged using a Nikon Eclipse TE2000-E inverted fluorescence microscope with a Photometrics Cascade 650 camera (Roper Scientific) and MetaVue 6.2r2 imaging software (Universal Imaging).

\section{Western blot analysis}

The monolayers were washed once with ice-cold PBS and scraped from the silicone membranes with a plastic scraper in the presence of RIPA extraction buffer $(1 \mathrm{mM} \mathrm{NaHCO} 3,2 \mathrm{mM}$ PMSF, $1 \mathrm{mM} \mathrm{Na} 3 \mathrm{VO}$, $5 \mathrm{mM}$ EDTA, 10\% protease and phosphatase inhibitor cocktail tablet and $1 \%$ Triton-X) followed by $30 \mathrm{~s}$ sonication on ice. Protein concentration was determined with the Protein determination kit from Cayman chemical (Ann Harbor, Mi) using the spectrophotometer Synergy HT from Biotek. Western blotting was carried out by standard techniques, loading $30 \mu \mathrm{g}$ of protein into gradient precast-gels from Biorad, (Berkeley, $\mathrm{Ca}$ ) and incubating overnight with antibodies to NFKB (p50/P105 dilution 1:800), NFKB (p65 dilution 1:1000) and CDH5 and the constitutively expressed protein $\beta$-actin from Cell Signalling Technologies (Beverly, MA), followed by specific secondary HRP conjugated anti-rabbit, anti- 
mouse and anti-goat IgG from Cell Signalling Technologies (Beverly, MA). The blots were scanned with the Biorad western blot scanner and quantified with Image J software.

\section{Hemodynamic Simulator}

The hemodynamic simulator is described in detail in (S1 File). Briefly, it is based on the principle of a parallel plate flow chamber [12], but the upper plate is comprised of an elastic silicone membrane with the plated EC that is stretched in a direction perpendicular to the flow direction. A rocker arm mechanism provides the periodic stretching of the upper membrane with a defined strain (S1 \& S2 Figs). This mechanism is mechanically linked to a valve that converts a steady flow pressure head into a sinusoidal flow (WSS) with defined mean and amplitude. The phase angle between the strain (CS) and the flow (in phase with the WSS) defines the SPA, as shown in (S2 \& S3 Figs). This can be varied by rotating the mechanical linkage between the valve and the rocker arm.

\section{Plan of experiments}

To explore how endothelial cells acquire different phenotypes in response to vascular pulsatile WSS and CS at SPA characteristic of athero-protective and athero-prone regions, we used the hemodynamic simulator to reproduce the same sinusoidal WSS and CS waveforms, but at different phase angles. Changes in the expression of 39 genes, after 7 hours of mechanical stimulation, were studied. This time point was selected for comparison because EC are considered nearly flow-adapted with respect to gene expression after this time exposure. Details of the imposed WSS and CS conditions are given below.

Oscillatory flow with highly asynchronous SPA. Oscillatory flow with $10 \pm 10$ (mean \pm amplitude) dyn $/ \mathrm{cm}^{2}$ WSS, $4 \pm 4 \% \mathrm{CS}$, frequency $=1 \mathrm{~Hz}$, and SPA of $-180^{\circ}$ (atheroprone).

Oscillatory flow with synchronous SPA. Oscillatory flow with $10 \pm 10 \mathrm{dyn} / \mathrm{cm}^{2}$ WSS, $4 \pm 4 \% \mathrm{CS}$, frequency $=1 \mathrm{~Hz}$, and SPA $=0^{\circ}$ (atheroprotective).

Static control. No hemodynamic forces were applied on the silicon substrate. No flow (WSS $\left.=0 \mathrm{dyn} / \mathrm{cm}^{2}\right)$, and no strain (CS $=0 \%$ ).

Note that in each dynamic case the mean WSS is typical of arterial flow in a non-separated flow zone and that there is no flow reversal (OSI $=0)$. The CS is in a normal physiological range. The mean and amplitude of WSS and CSS do not vary between conditions, only the SPA.

\section{Data analysis}

Results are presented as mean \pm SEM obtained from at least eleven independent experiments for gene expression and independent experiments for Western blots $(\mathrm{n}=6$ for NFKB, and $\mathrm{n}=3$ for CDH5). Samples were obtained from monolayers that did not show damage or desquamation. Statistical analysis was performed by one-way analysis of variance (ANOVA) with either the least significant difference (LSD) test or Tamhane's $\mathrm{T}^{2}$ test (depending on Levene's statistic for homogeneity of variance) using SPSS 20.0 software tool. Difference in means were considered significant if $\mathrm{P}<0.1$.

\section{Results}

\section{Cell viability and morphology}

BAECs were exposed to WSS $\left(10 \pm 10 \mathrm{dyn} / \mathrm{cm}^{2}\right)$ and CS $(4 \pm 4)$ for $7 \mathrm{~h}$ in the hemodynamic simulator. The cells remained viable, with no signs of injury or desquamation, throughout the experiments at $\mathrm{SPA}=-180^{\circ}$ and $\mathrm{SPA}=0^{\circ}$. Staining with PI showed no increase in dead cells 

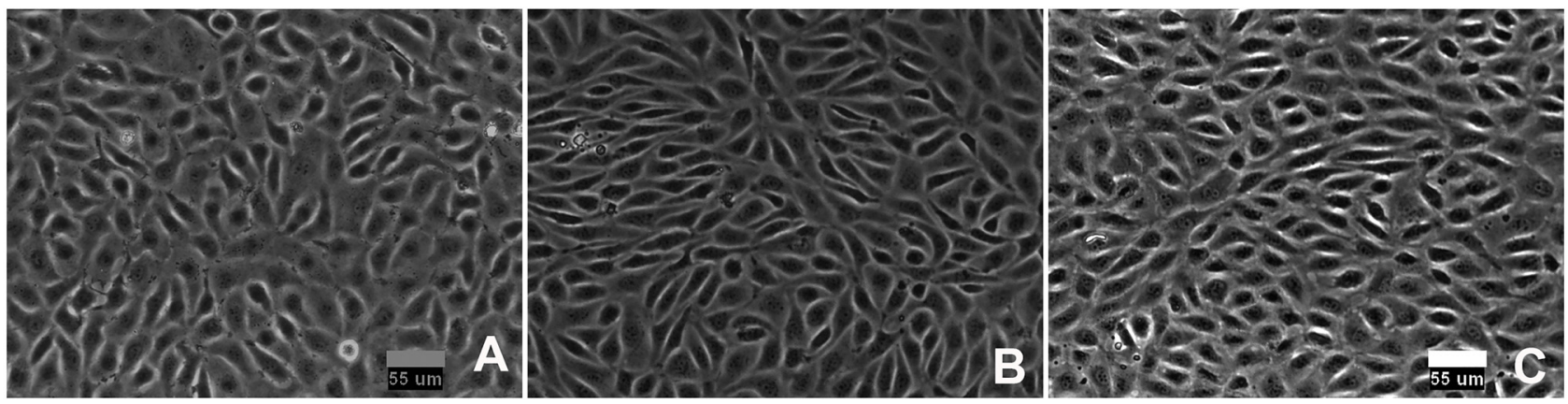

Fig 2. Endothelial cells seeded on the inner surface of silicone substrates. (A) Control conditions. ECs formed a confluent monolayer that has a cobblestone appearance. (B) After 7-h-exposure to WSS $(10 \pm 10$ dynes $/ \mathrm{cm} 2)$ and CS $(4 \pm 4 \%)$ at SPA $=0^{\circ}$ and $(C)$ SPA $=-180^{\circ}$. ECs remained confluent but showed subtle morphological changes. Flow is from left to right; strain is perpendicular to flow.

doi:10.1371/journal.pone.0129952.g002 


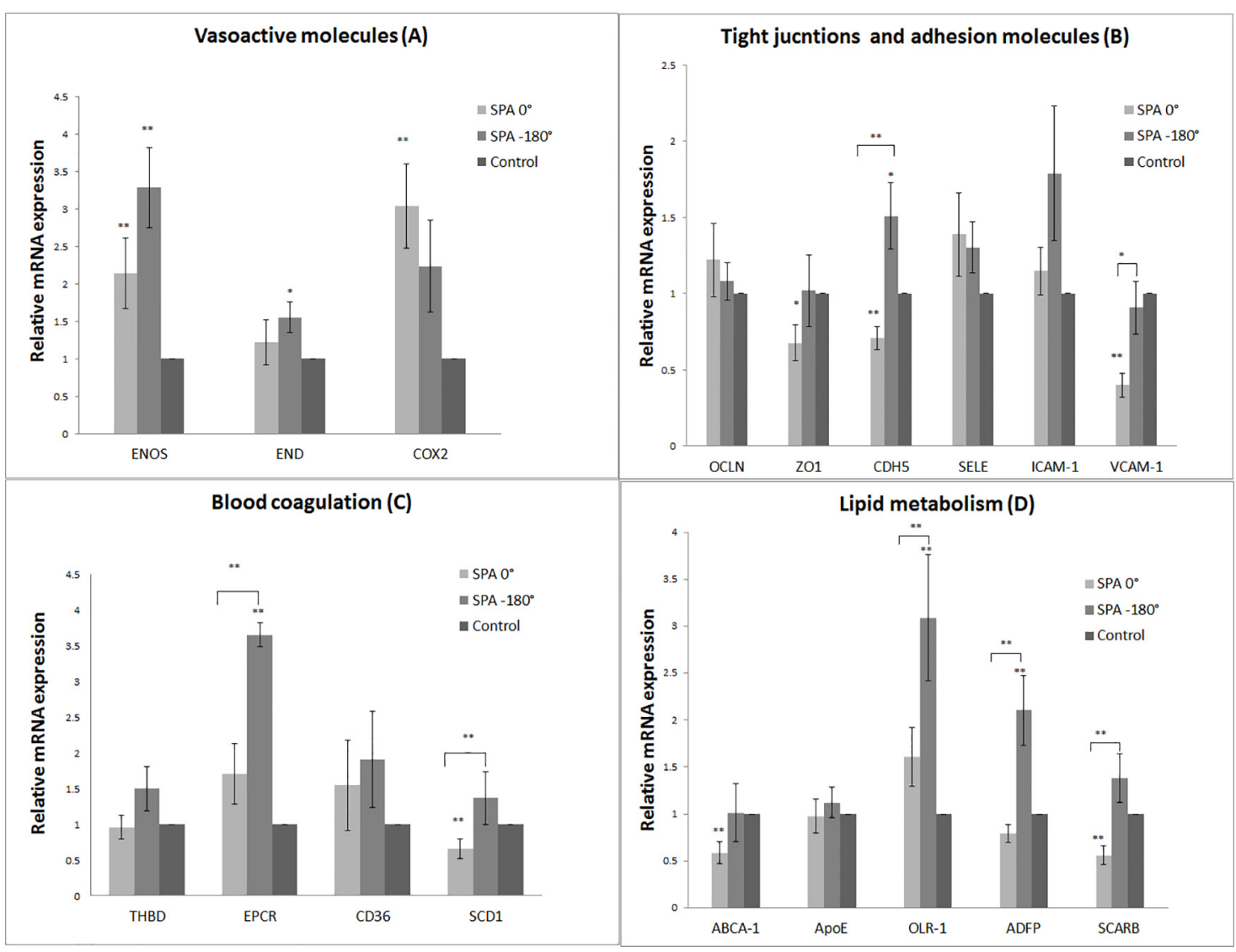

Fig 3. Hemodynamic influences on gene expression. Asynchronous hemodynamic conditions significantly increased the expression of the adhesion molecules $\mathrm{CDH} 5$ and VCAM-1 (B). Asynchronous hemodynamic conditions significantly increased EPCR and SCD1 mRNA levels (C). Asynchronous hemodynamic conditions significantly increased the mRNA levels of transcription regulators OLR-1, ADFP, and SCARB1 (D) ** $p<0.05,{ }^{*} p<0.1$ indicate significant differences for SPA $0^{\circ}$ with respect to control or SPA $-180^{\circ}$ with respect to control. An overbar indicates pairwise significant difference between SPA $0^{\circ}$ and SPA $-180^{\circ} .(n=11)$

doi:10.1371/journal.pone.0129952.g003

CDH-5 ( 1.4-fold) and ZO1 ( 1.5-fold) mRNA levels relative to static controls. Synchronous WSS and CS significantly decreased VCAM-1 ( 2.2-fold) mRNA levels compared with asynchronous hemodynamics and static controls. For the asynchronous hemodynamic condition, VCAM-1 mRNA expression stayed at the control level.

\section{Blood coagulation gene expression}

We analyzed the regulation of mRNA levels for the blood coagulation factors Thrombomodulin (THBD/TM), endothelial protein c-receptor (EPCR) and syndecan-1 (SCD1), and the cell surface receptor cluster of differentiation (CD36) as shown in Fig 3C. Asynchronous hemodynamics significantly increased EPCR mRNA levels compared to static controls (3.6-fold). In addition asynchronous hemodynamics increased EPCR mRNA levels compared to the synchronous case (2.1-fold). Synchronous hemodynamics significantly decreased the SDC-1 mRNA levels compared with asynchronous hemodynamics (2.2-fold).

\section{Lipid metabolism genes expression}

We analyzed the regulation of mRNA levels for the lipid transporter ABCA-1, Apolipoprotein E (apoE), oxidized LDL receptor-1 (ORL1), Adipose Differentiation-Related Protein / 


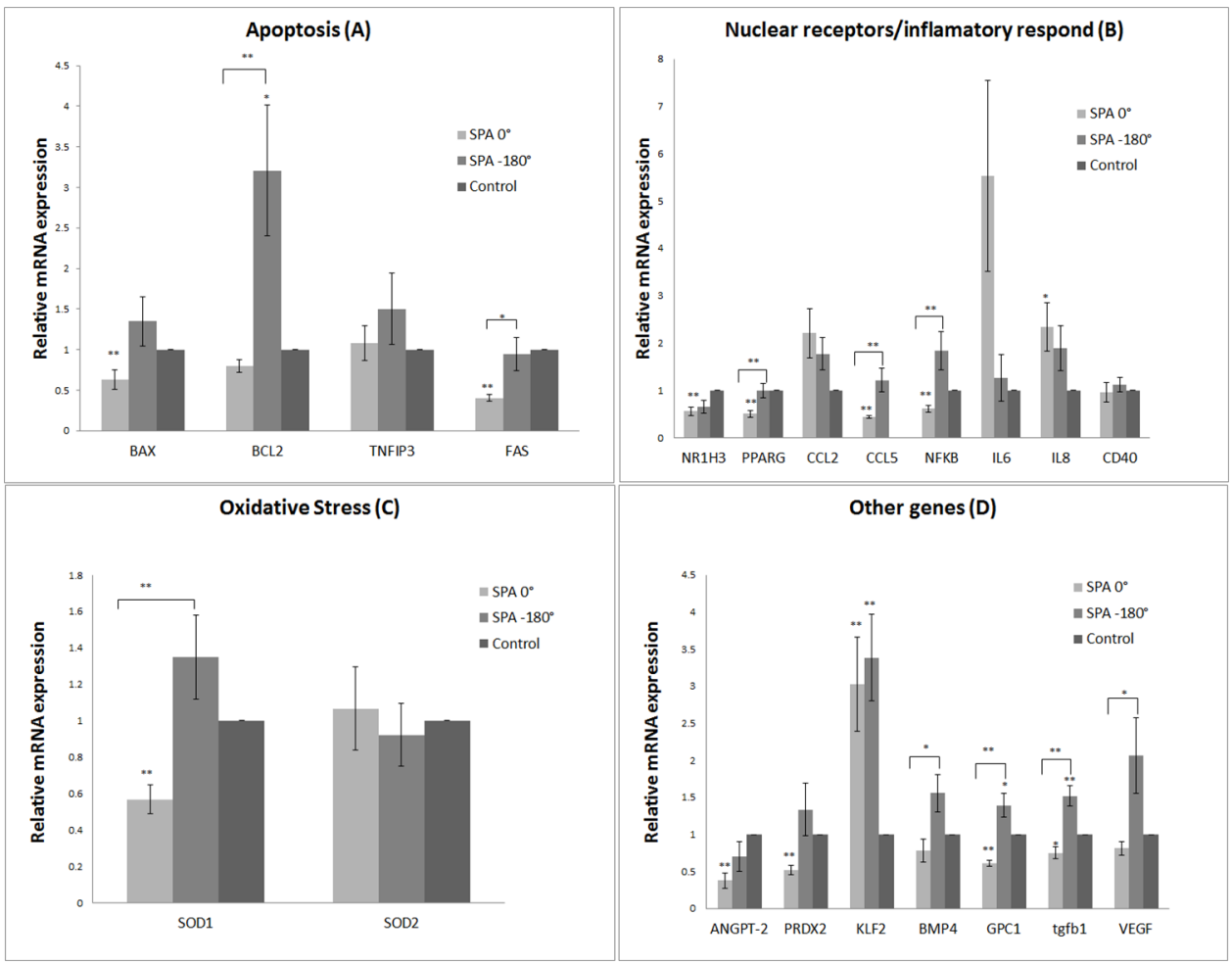

Fig 4. Hemodynamic influences on gene expression. Asynchronous hemodynamic conditions significantly increased the levels of mRNA of the apoptosis factor BCL2. Synchronous hemodynamics significantly reduced BAX and FAS mRNA levels (A). Asynchronous hemodynamics significantly increased the mRNA levels of PPARG, CCL5 and NFKB relative to synchronous conditions (B). Synchronous hemodynamics significantly decreased the mRNA levels of SOD1 compared to controls and SPA $=-180^{\circ}$ (C). Asynchronous hemodynamics significantly increased the mRNA levels of BMP4, GPC1, TGFb1 and VEGF compared to SPA $0^{\circ}$. Synchronous hemodynamic conditions decreased the gene expression of ANGTP2 and PRDX2 compared to control (D). $(n=11)$.

doi:10.1371/journal.pone.0129952.g004

Adipophilin (ADFP), and Scavenger receptor class B type 1 (SCARB-1 / SR-B1) as shown in Fig 3D. Synchronous hemodynamic conditions significantly reduced ABCA-1 mRNA levels (1.6-fold) compared with control. Asynchronous conditions very significantly augmented ORL-1 mRNA levels by 3.1-fold compared with static controls and by 2 -fold compared with synchronous hemodynamics. Asynchronous conditions significantly increased ADFP mRNA levels by 2.8 -fold compared with synchronous hemodynamics and by 2.3 -fold compared with static controls. Synchronous hemodynamic conditions significantly reduced SCARB-1 mRNA levels (2.5-fold) compared with asynchronous hemodynamics.

\section{Apoptosis gene expression}

We analyzed the gene expression of apoptosis regulating proteins: the BCL2-associated X (BAX), B-cell lymphoma 2 (BCL2), Tumor Necrosis Factor-Alpha-Induced Protein-3 (TNFAIP-3 / A20), and Apoptosis Stimulating Factor (Fas) as shown in Fig 4A. Synchronous condition decreased BAX ( 1.7-fold) mRNA levels compared with control. Asynchronous conditions very significantly increased BCL2 mRNA levels by 3.2 -fold compared with static control and by 4.0 -fold compared to synchronous hemodynamic conditions. Synchronous conditions significantly reduced FAS mRNA levels ( 2.5-fold) compared with static control and asynchronous conditions. 


\section{Nuclear receptors and inflammatory response gene expression}

We analyzed the regulation of Nuclear Receptor Sub-Family 1, Group H, Member 3 (NR1H3), Peroxisome proliferator-activated receptor G (PPARG) and the inflammatory response genes Chemokine (C-C Motif) Ligand-2 (CCL-2), Chemokine (C-C Motif) Ligand-5 / RANTES (CCL-5), interleukins (IL6, IL8), and cluster of differentiation CD40, and the transcriptional

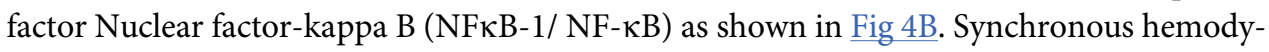
namic conditions significantly reduced NR1H3 mRNA levels $(\sim 1.8$-fold) compared with static control. Synchronous conditions significantly reduced PPARG mRNA levels by 2 -fold compared with static control and asynchronous conditions. Synchronous hemodynamics significantly reduced CCL5 mRNA levels by 2.3-fold compared with static controls and by 2.8 -fold compared to asynchronous hemodynamic conditions. Synchronous conditions significantly reduced NFKB mRNA levels by 1.62-fold compared with static controls and by 3 -fold compared to asynchronous conditions. Synchronous conditions increased IL- $8 \mathrm{mRNA}$ levels by 2.34-fold compared with static controls.

\section{Oxidative stress gene expression}

We analyzed the regulation of Superoxide Dismutase-1 / Cu, Zn Superoxide Dismutase (SOD1) and Superoxide dismutase-2 (SOD2) (Fig 4C). Synchronous conditions significantly reduced SOD1 mRNA levels by 1.8-fold compared with static control and by 2.3 -fold compared to asynchronous conditions. There were no significant effects on SOD2.

\section{Other genes}

We analyzed the regulation of Angiopoietin-2 (ANGPT-2 /Ang-2), peroxiredoxin-2 (PRDX2), Kruppel-like factors 2 (KLF2), bone morphogenetic protein-4 (BMP4), glypican-1 (GPC-1), transforming growth factor beta-1 (TGFb1) and vascular endothelial growth factor (VEGF) (Fig 4D). Synchronous conditions significantly decreased ANGPT-2 mRNA levels by 2.6-fold compared with static controls. Synchronous conditions significantly reduced PRDX-2 mRNA levels ( 2-fold) compared with static controls. Asynchronous and synchronous conditions significantly increased KLF-2 mRNA levels by 3.0-fold and 3.4-fold, respectively, compared with static controls, but they were not different from each other. Asynchronous conditions significantly increased BMP4 mRNA levels by 2.0-fold compared with synchronous conditions. Asynchronous conditions significantly increased GPC-1 mRNA levels by 1.4-fold compared with static control and by 2.2-fold compared to synchronous conditions. Asynchronous conditions significantly increased TGFb1 mRNA levels by 1.5-fold compared with static control and by 2.0-fold compared to synchronous hemodynamic conditions. Asynchronous conditions significantly increased VEGF mRNA levels by 2.5 -fold compared to synchronous hemodynamic conditions.

\section{NFKB staining in BAECs exposed to SPA $=0^{\circ}$ and SPA $=-180^{\circ}$}

$\mathrm{NF \kappa B}$ gene expression was significantly up-regulated by $\mathrm{SPA}=-180^{\circ}$ compared to $\mathrm{SPA}=0^{\circ}$ (Fig 4B). To assess the effects of SPA on the protein expression and localization of NFKB p105/ p50 and NFKB p65 we compared the immunostaining of NFKB (p105/p50 and p65) on BAECs exposed to asynchronous or synchronous hemodynamics for $7 \mathrm{~h}$. Our results indicate that asynchronous hemodynamics induce the translocation of NFKB p105/p50 and p65 to the nucleus as shown in the Fig $5 \mathrm{~b}$ and $5 \mathrm{e}$. The localization of NFKB is entirely cytoplasmic for synchronous hemodynamics (Fig $5 \mathrm{a}$ and $5 \mathrm{~d}$ ). 

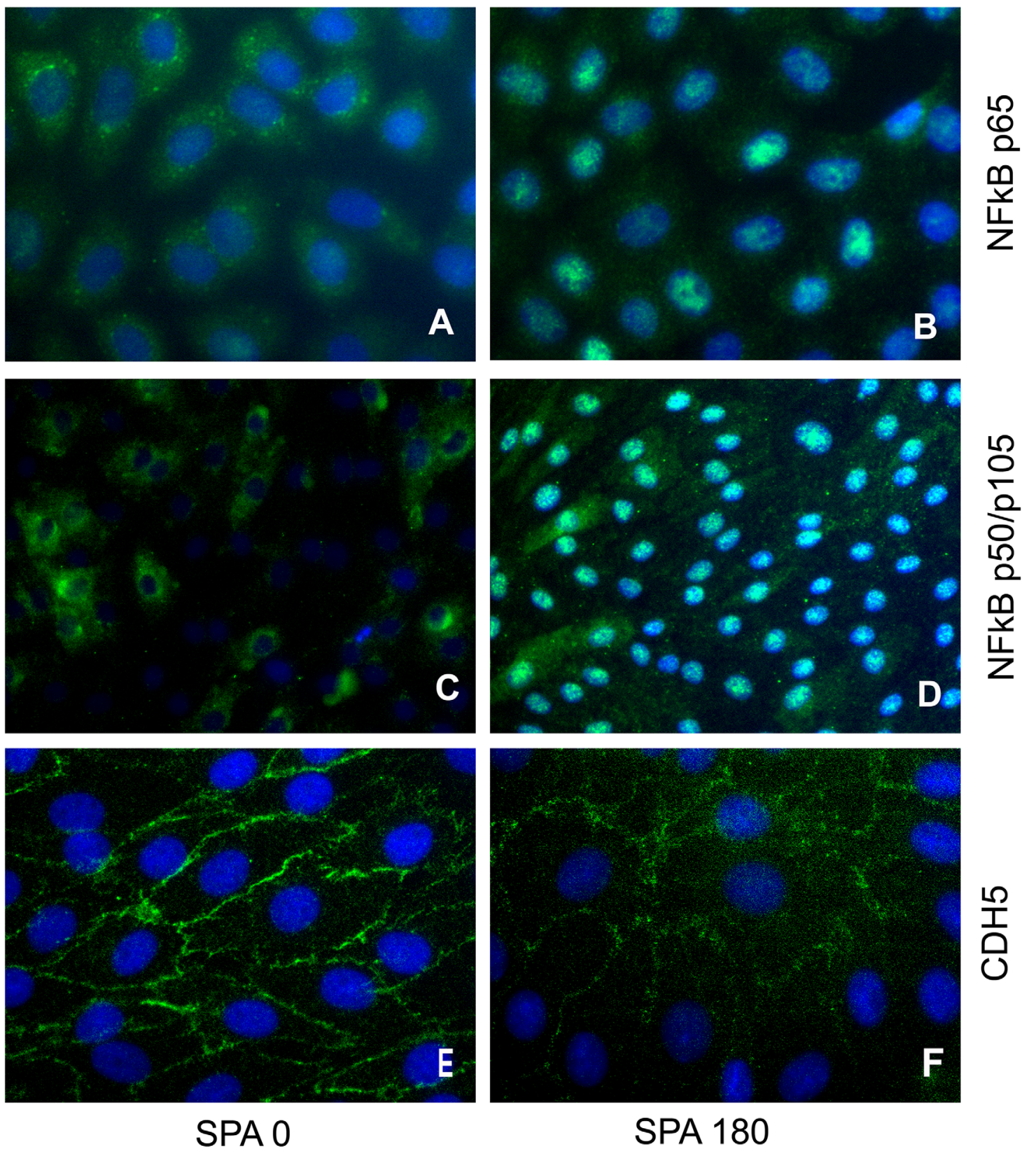

\section{SPA 180}

Fig 5. SPA modulates localization of NFKB p105/p50, NFKB p65 and CDH5. BAEC were exposed to asynchronous or synchornous condition for 7h. Stainings for NFKB p105/p50 (B) and p65 (D) were localized in the citoplasm and the nucleos for EC exposed to SPA $=-180$. NFKB localization where entirely citoplasmatic for $E C$ exposed to SPA $=0(A, C)$. The distribution for $\mathrm{CDH} 5$ were continous around the entire periphery of the cells after 7 when cells where exposed to SPA $=0$ (E). Exposure of EC to SPA $=-180$ for 7 hours resulted in an intermitted pattern of $C D H 5(F)$. images showed here are representative resutl from 3 individual experiments.

doi:10.1371/journal.pone.0129952.g005

$\mathrm{CDH}-5$ staining in BAECs exposed to SPA $=0$ and SPA $=-180$ in vitro

CDH5 (VE-cadherin) gene expression was significantly up-regulated by SPA $=-180$ compared to SPA $=0$ (Fig 3B). To assess the effects of SPA on the protein expression and localization of $\mathrm{CDH} 5$, we compared the immunostaining of $\mathrm{CDH} 5$ on BAECs exposed to asynchronous and synchronous hemodynamics. Under synchronous conditions for $7 \mathrm{~h}, \mathrm{CDH} 5$ staining was continuous and distributed around the entire periphery of endothelial cells (Fig 5F) indicating 
robust adherens junction formation. In contrast, after exposure to asynchronous hemodynamics for $7 \mathrm{~h}, \mathrm{CDH} 5$ staining at cell-cell junctions became intermittent and in some areas not detectable (Fig 5G) indicating weakened adherens junctions.

\section{Relative Protein expression of NFKB and CDH5}

Asynchronous conditions increased the level of protein expression for NFKB p105, p50 and p65 compared to synchronous hemodynamics (Fig 6). These observations are consistent with the hypothesis that asynchronous hemodynamics is atheroprone and indirectly indicate EC under asynchronous hemodynamics initiate an inflammatory state. We found that asynchronous conditions significantly increased protein expression of NFKB p50 by 1.9 fold $(\mathrm{p}=0.001)$ and NFKB p105 by 1.98 fold $(\mathrm{p}=0.058)$ compared to SPA $=0^{\circ}$ similarly, asynchronous hemodynamics increased the protein expression of NFKB p65 by 1.98 fold $(p=0.02)$ compared to $\mathrm{SPA}=0^{\circ}$. SPA $=0^{\circ}$ or SPA $=-180^{\circ}$ did not have any effect on the level of protein expression of $\mathrm{CDH} 5(\mathrm{p}=0.3)$.

\section{Discussion}

Most in vitro studies of the role of hemodynamics in atherosclerosis have emphasized the analysis of isolated forces, mainly fluid shear stress, but also cyclic stress (strain). Different hemodynamic conditions such as low mean wall shear stress, disturbed flow, and reversal flow (high OSI) have been associated with the localization and development of atherosclerosis. The coronary arteries, the locations most prone to atherosclerosis, exhibit highly asynchronous hemodynamic conditions (SPA close to $-180^{\circ}$ ); approximately $50 \%$ of the total coronary blood flow occurs in early diastole, $25 \%$ in late diastole, and only $25 \%$ in systole [13]. SPA close to $-180^{\circ}$ also occurs on the outer wall of bifurcations and other characteristic atheroprone sites due to geometric factors [3]. Hypertension, vessel stiffness due to aging, and the increase in the severity of stenosis are major risk factors in several cardiovascular diseases. These factors have been shown to induce a more negative SPA $[14,15]$.

Asynchronous and synchronous hemodynamic waveforms differentially regulate endothelial gene expression. We have shown that identical WSS and CS waveforms elicit different gene expression profiles depending only on differences in the stress phase angle. Statistical analysis based on duplicate sets of cDNA template experiments using eleven different biological samples from each experimental condition (SPA $=0^{\circ}$ and $\left.\mathrm{SPA}=-180\right)$ revealed that 17 out of 38 genes were up-regulated by asynchronous hemodynamics relative to synchronous hemodynamics and classified as atheroprone, atheroprotective or of undetermined role in the disease (Table 2). Notably, no genes were upregulated significantly by synchronous conditions relative to asynchronous hemodynamics.

Asynchronous hemodynamic conditions elicited an up-regulation of genes across all the different gene groups. Direct comparison of SPA $=0^{\circ}$ and $\mathrm{SPA}=-180^{\circ}$ conditions illustrated the differences in gene profile pattern. Most significantly, we showed that asynchronous hemodynamics $\left(\mathrm{SPA}=-180^{\circ}\right)$ evoke mostly athero-prone genes relative to synchronous hemodynamics $\left(\mathrm{SPA}=0^{\circ}\right)$.

Asynchronous hemodynamics induced the expression of the transcription factor NFKB p50/ p105 and p65 which plays a central role in the regulation of inflammation, adhesion and proliferation genes- all precursors to the onset of atherosclerosis [16-18]. In our study we have shown that asynchronous hemodynamics upregulated the expression of the following possible NFKB-1 target genes: VCAM-1 [19] which plays a major role in the initiation of atherosclerosis by facilitating the recruitment of monocytes to the arterial intima [20]; VEGF [21] which induces the migration and proliferation of monocytes and endothelial cells, vascular permeability and 


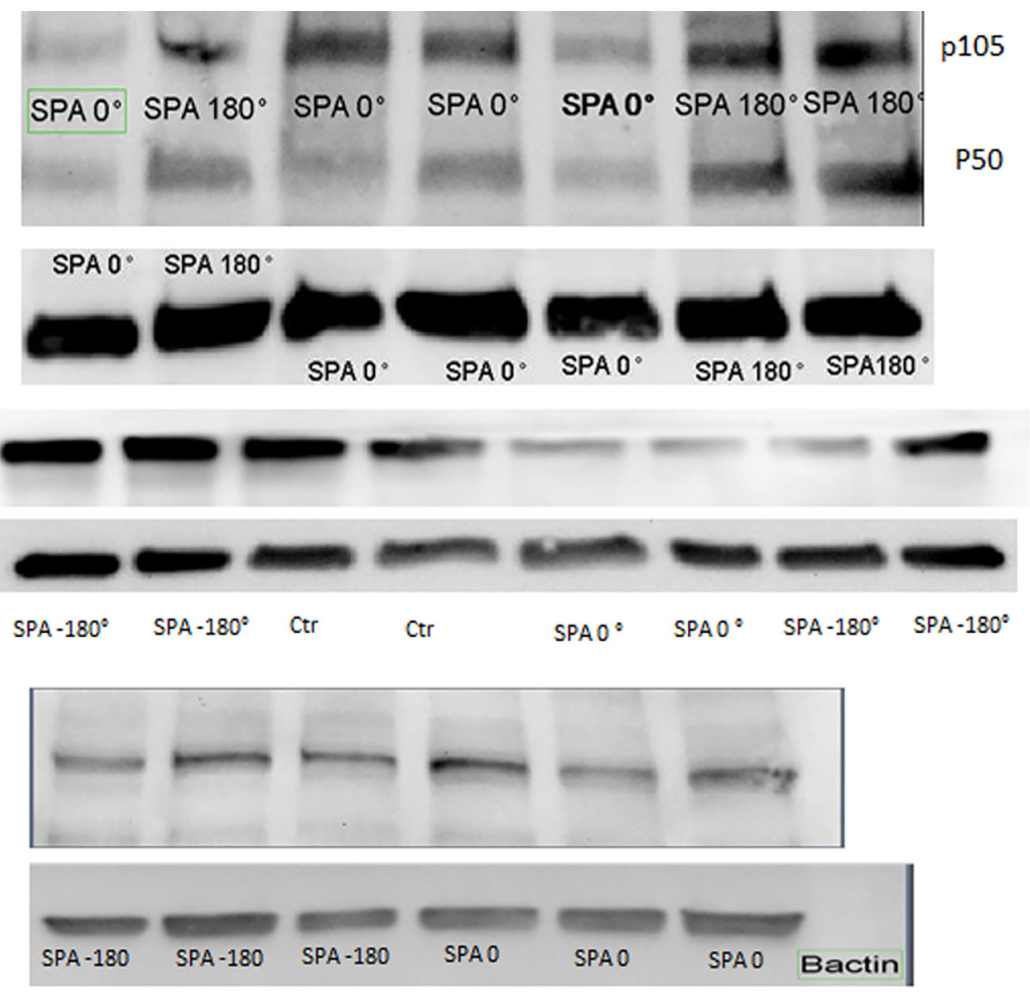

A

\section{NFkB p105/p50, NFkB p65 protein expression}

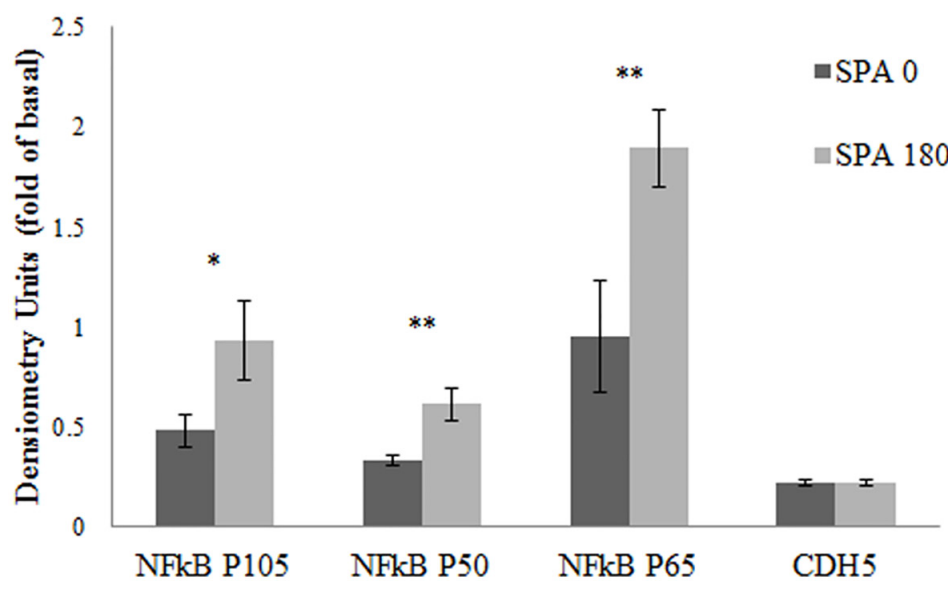

Fig 6. SPA modulates the protein expression levels of NFkB p105/p50 and NFkB p65 but does not affect CDH5. BAEC monolayer were exposed to WSS and CS with either SPA $=0$ or SPA $=-180$ during 7 hours. Cell lysates from different samples ( $n=6$ each condition) were separated in gradient SDS-PAGE, and the proteins were transferred to nitrocellulose membranes. Nitrocellulose membranes were split into two parts for immunoblotting with NFKB p105/p50 or NFkB p65 using ßactin as the endogenous control. Representative blots are shown in Fig 6 . Samples were analysed by densitometry and normalized by the $\beta$ actin control; then the relative protein expressions at SPA $=-180$ and SPA $=0$ were compared. The bar graphs in (A) represent the quantification of 6 individual experiments (mean \pm SEM). SPA $=-180$ increases the expression of NFKB p50 by 1.9 fold compared to SPA $=0(p=0.001)$ and the expression of NFKB p105 by 1.98 fold $(p=0.058)$. The bar in (B) suggest that SPA $=-180$ increase the expression of the transcriptional factor NFKB p65 $(n=8)$ by 1.98 fold $(p=0.002)$ (ANOVA, all $p<0.05)$. SPA did not affect the CDH5 protein expression levels ( $n=3$ for each condition) (ANOVA $p>0.05$ ) as shown in panel $B$.

doi:10.1371/journal.pone.0129952.g006 
Table 2. Endothelial genes up-regulated by the athero-prone condition SPA $=-180^{\circ}$ relative to the athero-protective condition $\mathrm{SPA}=0^{\circ}$.

\begin{tabular}{|c|c|c|c|c|}
\hline Gene Bank $N^{\circ}$ & Gene name & Atheroprone/atheroprotective ratio & Characteristic & p-Value \\
\hline BC151459.1 & Vascular Cell Adhesion Molecule-1 (VCAM-1) & 2.3 & Proatherogenic & 0.073 \\
\hline М32976 & Vascular Endothelial Growth Factor (VEGF) & 2.5 & Proatherogenic & 0.099 \\
\hline XM_002694894 & Cadherin-5 (CDH-5 / VE-Cadherin) & 2.1 & Proatherogenic & 0.013 \\
\hline NM_174132.2 & Oxidized Low Density Lipoprotein Receptor-1 (OLR-1) & 2.7 & Proatherogenic & 0.047 \\
\hline BC102211 & Adipose Differentiation-Related Protein / Adipophilin (ADFP) & 2.8 & Proatherogenic & 0.01 \\
\hline BC102064 & Chemokine (C-C Motif) Ligand-5 / RANTES (CCL-5) & 2.8 & Proatherogenic & 0.034 \\
\hline DQ464067 & Nuclear Factor of Kappa(NFKB-1 / NF-kB) & 3.0 & Proatherogenic & 0.04 \\
\hline BC105344 & Bone Morphogenetic Protein-4 (BMP-4) & 2.0 & Proatherogenic & 0.066 \\
\hline M_001166068 & Transforming growth factor b1 (TGFB1) & 2.0 & Proatherogenic & 0.001 \\
\hline NM_174662 & Apoptosis Stimulating Factor (Fas) & 2.3 & Proatherogenic & 0.097 \\
\hline BC134513 & Scavenger Receptor, Class B, Type 1 (SCARB-1 / SR-B1) & 2.5 & Antiatherogenic & 0.033 \\
\hline BC102432 & Superoxide Dismutase-1 (SOD-1) & 2.4 & Antiatherogenic & 0.023 \\
\hline BC116074 & Endothelial Protein C Receptor (EPCR) & 2.1 & Antiatherogenic & 0.013 \\
\hline NM_001075924 & Syndecan-1 (SDC-1) & 2.5 & Indeterminate & 0.028 \\
\hline NM_181024 & Peroxisome Proliferator-Activated Receptor-g (PPAR-G) & 2.0 & Indeterminate & 0.043 \\
\hline NM_001166486 & B-Cell CLL/Lymphoma-2 (BCL-2) & 4.0 & Indeterminate & 0.04 \\
\hline BC105496 & Glypican-1 (GPC-1) & 2.3 & Indeterminate & 0.002 \\
\hline
\end{tabular}

doi:10.1371/journal.pone.0129952.t002 
that shows proatherogenic features such as enhancing LDL uptake but primarily limits the progression of atherosclerosis by inhibiting VCAM1 expression and monocyte migration [48]

Athero-prone waveforms alter the endothelial apoptosis state. Asynchronous hemodynamics increases the gene expression of FAS (pro-apoptotic) and BCL-2 (anti-apoptotic). The overall effects of these genes in the development of the disease are undetermined. A previous study showed that asynchronous hemodynamics increases apoptosis rate [49] which has been shown to increase endothelial permeability to LDL [50] leading to progression of disease.

Our results did not show any significant difference in mRNA levels for the tight junction protein genes OCLN-1 and ZO-1. A previous study showed that both synchronous and asynchronous hemodynamics had no effect on either OCLN-1 or ZO-1 protein expression after 12 hours [47].

Our results showed that ET-1 mRNA levels were not significantly altered from the basal level under any hemodynamic condition. These results agree with previous studies where it was observed that ET-1 gene expression was not significantly affected at SPA $=0^{\circ}$ or $-180^{\circ}$ after 5 hours [51]. Another study at unknown SPA (probably synchronous) showed that combined WSS and CS did not influence ET-1 mRNA expression, while isolated WSS decreased the gene expression of ET-1, and CS alone increased its expression [52, 53].

Both asynchronous and synchronous hemodynamics significantly increased the expression of three atheroprotective genes relative to static controls: ENOS, COX2 and KLF2 (Figs 3A and 4D). ENOS and COX2 are vasodilators that play an important role in homeostasis; KLF2 is a transcriptional factor which is more abundant in the high-shear regions resistant to atherosclerosis than in areas of disturbed flow and endothelial dysfunction. KLF2 inhibits the proinflammatory response of monocytes and lipid uptake, and inhibits NFkB transcriptional activity [54]

We also examined the expression and distribution of proteins whose genes were up-regulated by asynchronous relative to asynchronous conditions (Figs 5 and 6). In regard to $\mathrm{CDH} 5$, in atheroprone regions such as major curvatures and bifurcations the organization of intercellular junctions is not well defined resulting in increased EC layer permeability and vulnerability to leukocyte transmigration. In vivo studies of immunostaining of CDH5 have shown that it is highly expressed at EC borders in the abdominal aorta [55], which is a region protected from atherosclerosis with more synchronous hemodynamics $\left(\mathrm{SPA}=-45^{\circ}\right)$ [56], but $\mathrm{CDH} 5$ staining is markedly reduced in the stenotic region of arteries with stenosis and not detectable downstream of the stenotic region [55]. These regions are characterized by highly negative of SPA reaching values of $\mathrm{SPA}=-180^{\circ}$ downstream of the stenosis [57]. In the present study we observed that asynchronous hemodynamic upregulated the gene expression of CDH5 (Fig 3B), however this did not translate into upregulation of protein expression (Fig 6). But immunofluorescence staining (Fig 5E and 5F) showed a dramatic change in the localization of $\mathrm{CDH} 5$ and junctional reorganization that is similar to that observed in atheroprone regions. These are post-translational modifications that would not be indicated by gene expression. Our results suggest that $\mathrm{CDH} 5$ localization and organization may be regulated by the SPA.

On the other hand we found that $\mathrm{SPA}=-180^{\circ}$ increased the protein expression level for $\mathrm{NFKB}$ p105/p50 and NFkB p65 compared to SPA $=0^{\circ}$ (Fig 6), and this was consistent with the upregulation of gene expression for NFKB (Fig $4 \mathrm{~B}$ ). Interestingly, our results also indicated that $\mathrm{NF \kappa B}$ p105/p50 and NFKB p65 are translocated to the nucleus when EC are under asynchronous hemodynamics while it is totally localized in the cytoplasm when EC are under synchronous hemodynamics (Fig $5 \mathrm{~A}$ and $5 \mathrm{~B}$ ). It is well known that NFKB resides in the cytoplasm of the cell and upon activation translocates to the nucleus $[58,59]$. Thus we have shown that asynchronous SPA induces a similar atherogenic translocation of NFKB.

In conclusion, we have reported the results of novel experiments in which BAECs were exposed to a well-defined combination of WSS and CS, accurately simulating synchronous 
(athero-protective), and asynchronous (athero-prone) hemodynamics. We have shown that asynchronous hemodynamics up-regulate many atheroprone genes including those that modulate pro-inflammatory signal transduction or produce components that enhance the binding of lipoproteins. Of special note, we showed that endothelial cells exposed to asynchronous hemodynamics acquire a pro-inflammatory phenotype with enhanced expression of the important chemokine CCL5 and the activation of NFKB as well as the activation of adhesion molecules such as VCAM-1 and several growth factors including VEGF and TGF $\beta 1$. We also reported post translational modifications of $\mathrm{CDH} 5$ and $\mathrm{NF \kappa B}$ induced by asynchronous SPA that are consistent with an atheroprone environment. Based on these results, the SPA appears to be an important parameter characterizing the hemodynamic environment.

\section{Supporting Information}

S1 File. Hemodynamic simulator and strain and flow characterization. Analysis of the flow dynamics in the novel device and strain characterization of silicone substrate sheets. Table A in S1 File. PCR primer sequences.

(DOCX)

S1 Fig. Schematic of the hemodynamic simulator test section and the valve phase link station. The bioreactor combines a customized pulsatile flow valve mechanically linked to a membrane stretching mechanism and a parallel flow chamber. Different SPA values can be generated by changing the configuration of the phase link station. (TIF)

S2 Fig. Strain characterization. Displacement over time of reference markings recorded by video, showing a sinusoidal displacement when the reference markings were tracked over 8 complete cycles for a CS $=4 \pm 4 \%$. The strain characterization of the silicone substrate using computational software ABAQUS determined a uniform strain distribution in the center of the flow channel at a maximum strain of $10 \%$. The cells were plated in the uniform strain region. (TIF)

S3 Fig. Fluid flow analysis in real-time by data acquisition using software written in LabVIEW. The upper panel of the LabVIEW screen shows a typical flow waveform and the lower panel shows the associated FFT indicating very little contribution from the second or higher harmonics.

\section{Acknowledgments}

We like to thank Pablo Saez for his help with the strain characterization model of cell culture substrate.

This work was supported by NIH Grant HL 086543.

\section{Author Contributions}

Conceived and designed the experiments: RAA JMT. Performed the experiments: RAA. Analyzed the data: RAA. Contributed reagents/materials/analysis tools: RAA AP. Wrote the paper: RAA.

\section{References}

1. Qiu Y, Tarbell JM. Interaction between wall shear stress and circumferential strain affects endothelial cell biochemical production. J Vasc Res. 2000; 37(3):147-57. Medline:PMID: 10859473. 
2. Qiu Y, Tarbell JM. Numerical simulation of pulsatile flow in a compliant curved tube model of a coronary artery. J Biomech Eng. 2000; 122(1):77-85. Medline:PMID: 10790833.

3. Tada S, Tarbell JM. A computational study of flow in a compliant carotid bifurcation-stress phase angle correlation with shear stress. Annals of biomedical engineering. 2005; 33(9):1202-12. doi: 10.1007/ s10439-005-5630-1 PMID: 16133927.

4. Qiu Y, Tarbell JM. Computational simulation of flow in the end-to-end anastomosis of a rigid graft and a compliant artery. ASAIO journal. 1996; 42(5):M702-9. PMID: 8944971.

5. Tada S, Dong C, Tarbell JM. Effect of the stress phase angle on the strain energy density of the endothelial plasma membrane. Biophysical journal. 2007; 93(9):3026-33. doi: 10.1529/biophysj.106. 100685 PMID: 17660317; PubMed Central PMCID: PMC2025663.

6. Dancu MB, Tarbell JM. Coronary endothelium expresses a pathologic gene pattern compared to aortic endothelium: correlation of asynchronous hemodynamics and pathology in vivo. Atherosclerosis. 2007; 192(1):9-14. doi: 10.1016/j.atherosclerosis.2006.05.042 PMID: 16806232.

7. Joshi AK, Leask RL, Myers JG, Ojha M, Butany J, Ethier CR. Intimal thickness is not associated with wall shear stress patterns in the human right coronary artery. Arteriosclerosis, thrombosis, and vascular biology. 2004; 24(12):2408-13. doi: 10.1161/01.ATV.0000147118.97474.4b PMID: 15472129.

8. Peiffer V, Sherwin SJ, Weinberg PD. Does low and oscillatory wall shear stress correlate spatially with early atherosclerosis? A systematic review. Cardiovascular research. 2013. doi: 10.1093/cvr/cvt044 PMID: 23459102.

9. Steinman DA, Thomas JB, Ladak HM, Milner JS, Rutt BK, Spence JD. Reconstruction of carotid bifurcation hemodynamics and wall thickness using computational fluid dynamics and MRI. Magn Reson Med. 2002; 47(1):149-59. Medline:PMID: 11754454.

10. Ku DN, Giddens DP, Zarins CK, Glagov S. Pulsatile flow and atherosclerosis in the human carotid bifurcation. Positive correlation between plaque location and low oscillating shear stress. Arteriosclerosis. 1985; 5(3):293-302. Medline:PMID: 3994585.

11. Vandesompele J, De Preter K, Pattyn F, Poppe B, Van Roy N, De Paepe A, et al. Accurate normalization of real-time quantitative RT-PCR data by geometric averaging of multiple internal control genes. Genome Biol. 2002; 3(7):RESEARCH0034. Medline:PMID: 12184808.

12. Koslow AR, Stromberg RR, Friedman LI, Lutz RJ, Hilbert SL, Schuster P. A flow system for the study of shear forces upon cultured endothelial cells. J Biomech Eng. 1986; 108(4):338-41. Medline:PMID: 3795879.

13. Neuhaus KL, Sauer G, Tebbe U, Krause WB, Kreuzer H. Videodensitometric Measurement of FlowRates in Coronary Vessels. Z Kardiol. 1980; 69(3):235-. PubMed PMID: WOS:A1980JM89700230.

14. van Popele NM, Grobbee DE, Bots ML, Asmar R, Topouchian J, Reneman RS, et al. Association between arterial stiffness and atherosclerosis: the Rotterdam Study. Stroke. 2001; 32(2):454-60. Medline:PMID: 11157182.

15. Oscuii HN, Tafazzoli-Shadpour M, Ghalichi F. Biomechanical analysis of wall remodeling in elastic arteries with application of fluid-solid interaction methods. J Mech Med Biol. 2007; 7(4):433-47. PubMed PMID: WOS:000252269300005.

16. Li J-J, Gao R-L. Should atherosclerosis be considered a cancer of the vascular wall? Med Hypotheses. 2005; 64(4):694-8. Medline:PMID: 15694684.

17. Wilson SH, Caplice NM, Simari RD, Holmes DR Jr., Carlson PJ, Lerman A. Activated nuclear factorkappaB is present in the coronary vasculature in experimental hypercholesterolemia. Atherosclerosis. 2000; 148(1):23-30. PMID: 10580167.

18. Collins T, Cybulsky MI. NF-kappaB: pivotal mediator or innocent bystander in atherogenesis? The Journal of clinical investigation. 2001; 107(3):255-64. doi: 10.1172/JCl10373 PMID: 11160146; PubMed Central PMCID: PMC199202.

19. lademarco MF, McQuillan JJ, Rosen GD, Dean DC. Characterization of the promoter for vascular cell adhesion molecule-1 (VCAM-1). J Biol Chem. 1992; 267(23):16323-9. Medline:PMID: 1379595.

20. Galkina E, Ley K. Vascular adhesion molecules in atherosclerosis. Arteriosclerosis, thrombosis, and vascular biology. 2007; 27(11):2292-301. doi: 10.1161/ATVBAHA.107.149179 PMID: 17673705.

21. Leychenko A, Konorev E, Jijiwa M, Matter ML. Stretch-induced hypertrophy activates NFkB-mediated VEGF secretion in adult cardiomyocytes. PLoS One. 2011; 6(12):e29055. Medline:PMID: 22174951. doi: 10.1371/journal.pone.0029055

22. Celletti FL, Waugh JM, Amabile PG, Brendolan A, Hilfiker PR, Dake MD. Vascular endothelial growth factor enhances atherosclerotic plaque progression. Nature medicine. 2001; 7(4):425-9. doi: 10.1038/ 86490 PMID: 11283668. 
23. Barseghian $A$, Gawande D, Bajaj M. Adiponectin and vulnerable atherosclerotic plaques. Journal of the American College of Cardiology. 2011; 57(7):761-70. doi: 10.1016/j.jacc.2010.11.011 PMID: 21310310.

24. Lucerna M, Zernecke A, de Nooijer R, de Jager SC, Bot I, van der Lans C, et al. Vascular endothelial growth factor-A induces plaque expansion in ApoE knock-out mice by promoting de novo leukocyte recruitment. Blood. 2007; 109(1):122-9. doi: 10.1182/blood-2006-07-031773 PMID: 16990600.

25. Nagase M, Abe J, Takahashi K, Ando J, Hirose S, Fujita T. Genomic organization and regulation of expression of the lectin-like oxidized low-density lipoprotein receptor (LOX-1) gene. J Biol Chem. 1998; 273(50):33702-7. Medline:PMID: 9837956.

26. Ishino S, Mukai T, Kume N, Asano D, Ogawa M, Kuge Y, et al. Lectin-like oxidized LDL receptor-1 (LOX-1) expression is associated with atherosclerotic plaque instability-analysis in hypercholesterolemic rabbits. Atherosclerosis. 2007; 195(1):48-56. doi: 10.1016/j.atherosclerosis.2006.11.031 PMID: 17239887.

27. Murphy JE, Vohra RS, Dunn S, Holloway ZG, Monaco AP, Homer-Vanniasinkam S, et al. Oxidised LDL internalisation by the LOX-1 scavenger receptor is dependent on a novel cytoplasmic motif and is regulated by dynamin-2. Journal of cell science. 2008; 121(Pt 13):2136-47. doi: 10.1242/jcs.020917 PMID: 18544637.

28. Brasier AR. The nuclear factor-kappaB-interleukin- 6 signalling pathway mediating vascular inflammation. Cardiovasc Res. 2010; 86(2):211-8. Medline:PMID: 20202975. doi: 10.1093/cvr/cvq076

29. Schulick AH, Taylor AJ, Zuo W, Qiu CB, Dong G, Woodward RN, et al. Overexpression of transforming growth factor beta1 in arterial endothelium causes hyperplasia, apoptosis, and cartilaginous metaplasia. Proceedings of the National Academy of Sciences of the United States of America. 1998; 95 (12):6983-8. PMID: 9618525; PubMed Central PMCID: PMC22710.

30. Schmid H, Boucherot A, Yasuda Y, Henger A, Brunner B, Eichinger F, et al. Modular activation of nuclear factor-kappaB transcriptional programs in human diabetic nephropathy. Diabetes. 2006; 55 (11):2993-3003. Medline:PMID: 17065335.

31. Apostolakis S, Amanatidou V, Spandidos DA. Therapeutic implications of chemokine-mediated pathways in atherosclerosis: realistic perspectives and utopias. Acta pharmacologica Sinica. 2010; 31 (9):1103-10. doi: 10.1038/aps.2010.131 PMID: 20711227.

32. Huo Y, Schober A, Forlow SB, Smith DF, Hyman MC, Jung S, et al. Circulating activated platelets exacerbate atherosclerosis in mice deficient in apolipoprotein E. Nature medicine. 2003; 9(1):61-7. doi: 10. 1038/nm810 PMID: 12483207.

33. Stoneman VE, Bennett MR. Role of apoptosis in atherosclerosis and its therapeutic implications. Clinical science. 2004; 107(4):343-54. doi: 10.1042/CS20040086 PMID: 15230690.

34. Zhu N-L, Li C, Huang HH, Sebald M, Londhe VA, Heisterkamp N, et al. TNF-alpha represses transcription of human Bone Morphogenetic Protein-4 in lung epithelial cells. Gene. 2007; 393(1-2):70-80. Medline:PMID: 17350185.

35. Chang K, Weiss D, Suo J, Vega JD, Giddens D, Taylor WR, et al. Bone morphogenic protein antagonists are coexpressed with bone morphogenic protein 4 in endothelial cells exposed to unstable flow in vitro in mouse aortas and in human coronary arteries: role of bone morphogenic protein antagonists in inflammation and atherosclerosis. Circulation. 2007; 116(11):1258-66. doi: 10.1161/ CIRCULATIONAHA.106.683227 PMID: 17785623.

36. Singh NP, Nagarkatti M, Nagarkatti PS. Role of dioxin response element and nuclear factor-kappaB motifs in 2,3,7,8-tetrachlorodibenzo-p-dioxin-mediated regulation of Fas and Fas ligand expression. Molecular pharmacology. 2007; 71(1):145-57. doi: 10.1124/mol.106.028365 PMID: 16940415.

37. Schneider DB, Vassalli G, Wen S, Driscoll RM, Sassani AB, DeYoung MB, et al. Expression of Fas ligand in arteries of hypercholesterolemic rabbits accelerates atherosclerotic lesion formation. Arteriosclerosis, thrombosis, and vascular biology. 2000; 20(2):298-308. PMID: 10669624.

38. Nuotio K, Isoviita PM, Saksi J, ljas P, Pitkaniemi J, Sonninen R, et al. Adipophilin expression is increased in symptomatic carotid atherosclerosis: correlation with red blood cells and cholesterol crystals. Stroke. 2007; 38(6):1791-8. doi: 10.1161/STROKEAHA.106.478867 PMID: 17446422.

39. Naj AC, West M, Rich SS, Post W, Kao WH, Wasserman BA, et al. Association of scavenger receptor class B type I polymorphisms with subclinical atherosclerosis: the Multi-Ethnic Study of Atherosclerosis. Circulation Cardiovascular genetics. 2010; 3(1):47-52. doi: 10.1161/CIRCGENETICS.109.903195 PMID: 20160195; PubMed Central PMCID: PMC3359098.

40. Faraci FM, Didion SP. Vascular protection: superoxide dismutase isoforms in the vessel wall. Arteriosclerosis, thrombosis, and vascular biology. 2004; 24(8):1367-73. doi: 10.1161/01.ATV.0000133604. 20182.cf PMID: 15166009.

41. Taylor FB Jr., Peer GT, Lockhart MS, Ferrell G, Esmon CT. Endothelial cell protein C receptor plays an important role in protein C activation in vivo. Blood. 2001; 97(6):1685-8. PMID: 11238108. 
42. Miyazaki T, Taketomi Y, Takimoto M, Lei X-F, Arita S, Kim-Kaneyama J-r, et al. m-Calpain induction in vascular endothelial cells on human and mouse atheromas and its roles in VE-cadherin disorganization and atherosclerosis. Circulation. 2011; 124(23):2522-32. Medline:PMID: 22064597. doi: 10.1161/ CIRCULATIONAHA.111.021675

43. Wang WL, Haller CA, Wen J, Wang PY, Chaikof EL. Decoupled syndecan $1 \mathrm{mRNA}$ and protein expression is differentially regulated by angiotensin II in macrophages. J Cell Physiol. 2008; 214(3):750-6. doi: 10.1002/Jcp.21271. PubMed PMID: WOS:000253222700022. PMID: 18076060

44. Stanford KI, Bishop JR, Foley EM, Gonzales JC, Niesman IR, Witztum JL, et al. Syndecan-1 is the primary heparan sulfate proteoglycan mediating hepatic clearance of triglyceride-rich lipoproteins in mice. The Journal of clinical investigation. 2009; 119(11):3236-45. doi: 10.1172/JCI38251 PMID: 19805913; PubMed Central PMCID: PMC2769193.

45. Fico A, Maina F, Dono R. Fine-tuning of cell signaling by glypicans. Cell Mol Life Sci. 2011; 68(6):9239. doi: 10.1007/s00018-007-7471-6. PubMed PMID: WOS:000287578700001. PMID: 18087675

46. Qiao DH, Meyer K, Friedl A. Glypican-1 Stimulates Skp2 Autoinduction Loop and G(1)/S Transition in Endothelial Cells. Journal of Biological Chemistry. 2012; 287(8):5898-909. doi: 10.1074/jbc.M111. 325282. PubMed PMID: WOS:000300638000064. PMID: 22203671

47. Yang Z, Ming XF. Recent advances in understanding endothelial dysfunction in atherosclerosis. Clinical medicine \& research. 2006; 4(1):53-65. PMID: 16595793; PubMed Central PMCID: PMC1435659.

48. Marx N, Sukhova G, Murphy C, Libby P, Plutzky J. Macrophages in human atheroma contain PPARgamma: differentiation-dependent peroxisomal proliferator-activated receptor gamma(PPARgamma) expression and reduction of MMP-9 activity through PPARgamma activation in mononuclear phagocytes in vitro. The American journal of pathology. 1998; 153(1):17-23. PMID: 9665460; PubMed Central PMCID: PMC1852950.

49. Berardi DE, Tarbell JM. Stretch and Shear Interactions Affect Intercellular Junction Protein Expression and Turnover in Endothelial Cells. Cellular and molecular bioengineering. 2009; 2(3):320-31. doi: 10. 1007/s12195-009-0073-7 PMID: 20161517; PubMed Central PMCID: PMC2799298.

50. Cancel LM, Tarbell JM. The role of apoptosis in LDL transport through cultured endothelial cell monolayers. Atherosclerosis. 2010; 208(2):335-41. doi: 10.1016/j.atherosclerosis.2009.07.051 PMID: 19709659; PubMed Central PMCID: PMC2814958.

51. Dancu MB, Berardi DE, Vanden Heuvel JP, Tarbell JM. Asynchronous shear stress and circumferential strain reduces endothelial NO synthase and cyclooxygenase-2 but induces endothelin-1 gene expression in endothelial cells. Arteriosclerosis, thrombosis, and vascular biology. 2004; 24(11):2088-94. doi: 10.1161/01.ATV.0000143855.85343.0e PMID: 15345505.

52. Wang DL, Tang CC, Wung BS, Chen HH, Hung MS, Wang JJ. Cyclical strain increases endothelin-1 secretion and gene expression in human endothelial cells. Biochemical and biophysical research communications. 1993; 195(2):1050-6. Medline:PMID: 8373384.

53. Toda M, Yamamoto K, Shimizu N, Obi S, Kumagaya S, Igarashi $\mathrm{T}$, et al. Differential gene responses in endothelial cells exposed to a combination of shear stress and cyclic stretch. Journal of biotechnology. 2008; 133(2):239-44. doi: 10.1016/j.jbiotec.2007.08.009 PMID: 17850909.

54. Das H, Kumar A, Lin Z, Patino WD, Hwang PM, Feinberg MW, et al. Kruppel-like factor 2 (KLF2) regulates proinflammatory activation of monocytes. Proceedings of the National Academy of Sciences of the United States of America. 2006; 103(17):6653-8. doi: 10.1073/pnas.0508235103 PMID: 16617118; PubMed Central PMCID: PMC1458936.

55. Miao H, Hu YL, Shiu YT, Yuan S, Zhao Y, Kaunas R, et al. Effects of flow patterns on the localization and expression of VE-cadherin at vascular endothelial cell junctions: in vivo and in vitro investigations. Journal of vascular research. 2005; 42(1):77-89. doi: 10.1159/000083094 PMID: 15637443.

56. Mofrad MRK, Kamm RD. Cellular mechanotransduction: diverse perspectives from molecules to tissues. Cambridge: Cambridge University Press; 2010. xii, 465 p., 16 p. of plates $p$.

57. Sadeghi MR, Shirani E, Tafazzoli-Shadpour M, Samaee M. The effects of stenosis severity on the hemodynamic parameters-assessment of the correlation between stress phase angle and wall shear stress. Journal of biomechanics. 2011; 44(15):2614-26. doi: 10.1016/j.jbiomech.2011.08.017 PMID: 21906742.

58. Denk A, Goebeler M, Schmid S, Berberich I, Ritz O, Lindemann D, et al. Activation of NF-kappa B via the Ikappa B kinase complex is both essential and sufficient for proinflammatory gene expression in primary endothelial cells. The Journal of biological chemistry. 2001; 276(30):28451-8. Medline:PMID: 11337506.

59. Kempe S, Kestler H, Lasar A, Wirth T. NF-kappaB controls the global pro-inflammatory response in endothelial cells: evidence for the regulation of a pro-atherogenic program. Nucleic Acids Res. 2005; 33(16):5308-19. Medline:PMID: 16177180. 